\title{
Dexmedetomidine plays a protective role against leukocyte mediated lipid peroxidation and apoptosis in lung tissues of septic rats
}

\author{
Nurdan Bedirli', Gulsum Karabulut ${ }^{1}$, Umit Bagriacık ${ }^{2}$, Nalan Akyurek ${ }^{3}$ \\ Gazi University Medical Faculty, Anesthesiology ${ }^{1}$ Immunology ${ }^{2}$, Pathology 3 \\ Departments, Ankara, TURKEY
}

\section{Aim}

This study is designed to differentiate the effects of two different dosage of dexmedetomidine on lung injury induced by sepsis Moreover this study aimed to show whether the effects of dexmedetomidine on lung njury was related to systemic ICAM 1 release, neutrophil accumulation and apoptosis of alveolar epithelial cells.

\section{Methods}

42 Wistar rats weighing $250-300 \mathrm{~g}$ were noluded tn this study After CLP surgery and sham procedure, the rats an $5 \mathrm{DEX}$ group received 5 ug/kg/hr dexmedetomidine, rats $\mathrm{n}$ $10 \mathrm{DE}$ X group recelved $10 \mathrm{\mu g} / \mathrm{kg} / \mathrm{hr}$ dexmedetomidine $\mathrm{rats} \mathrm{n}$ sham and control groups received equal volume of saline 6 hours after $C L P$ rats of sham group and 6 rats of control, $5 \mathrm{DEX}$ and $10 \mathrm{DEX}$ groups were anesthetized with ketamine/xylasine combination and blood samples were withdrawn for the measurements of $\mathrm{TNF}, \alpha$ L $-1 \mathrm{\beta}$ and $\mathrm{CAM}-1$ analysis 24 hours after CLP lung samples were collected for MPO concentration, histologic examination, and tunel staining for apoptosis detection

\section{Results}

TNF-a levels were significantly lower n the $10 D E X$ group compared to both $5 \mathrm{DEX}$ and control groups serum ICAM 1 levels were significantly lower n $10 D E X$ compared to $5 D E X$ and control groups Activity of MPO ln lung significantly increased in control group 24 hour after CLP compared to sham and study groups MPO activity reduced significantly n lung tissue samples obtained from rats n $10 D E X$ group compared to $5 \mathrm{DEX}$ and control groups.

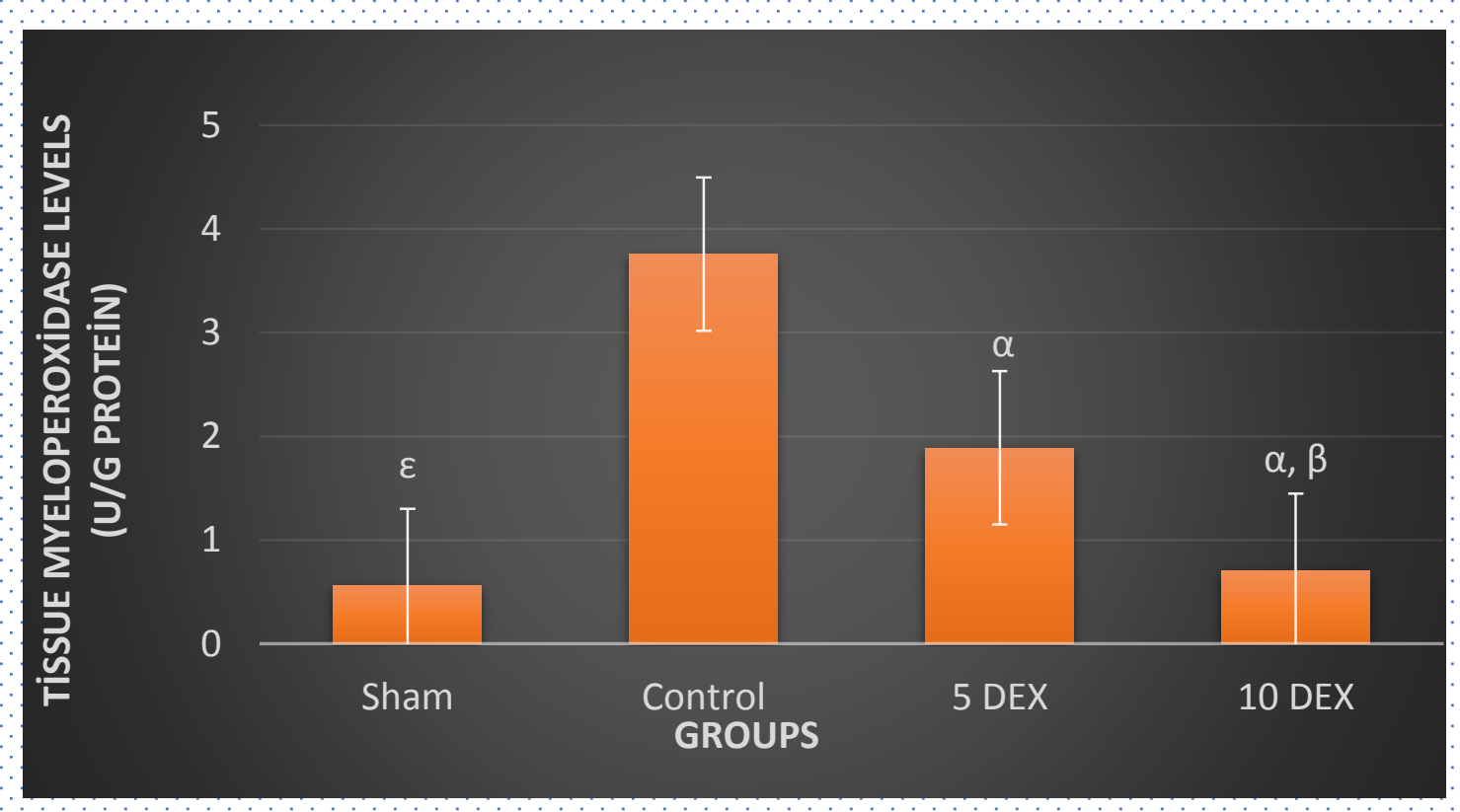

Figure 2 Lung tissue myeloperoxidase levels of rats 24 hour after $C L P$

The total lung njury score and apoptotic cell count were lower n both $5 D E X$ and $10 D E X$ groups than the control group.

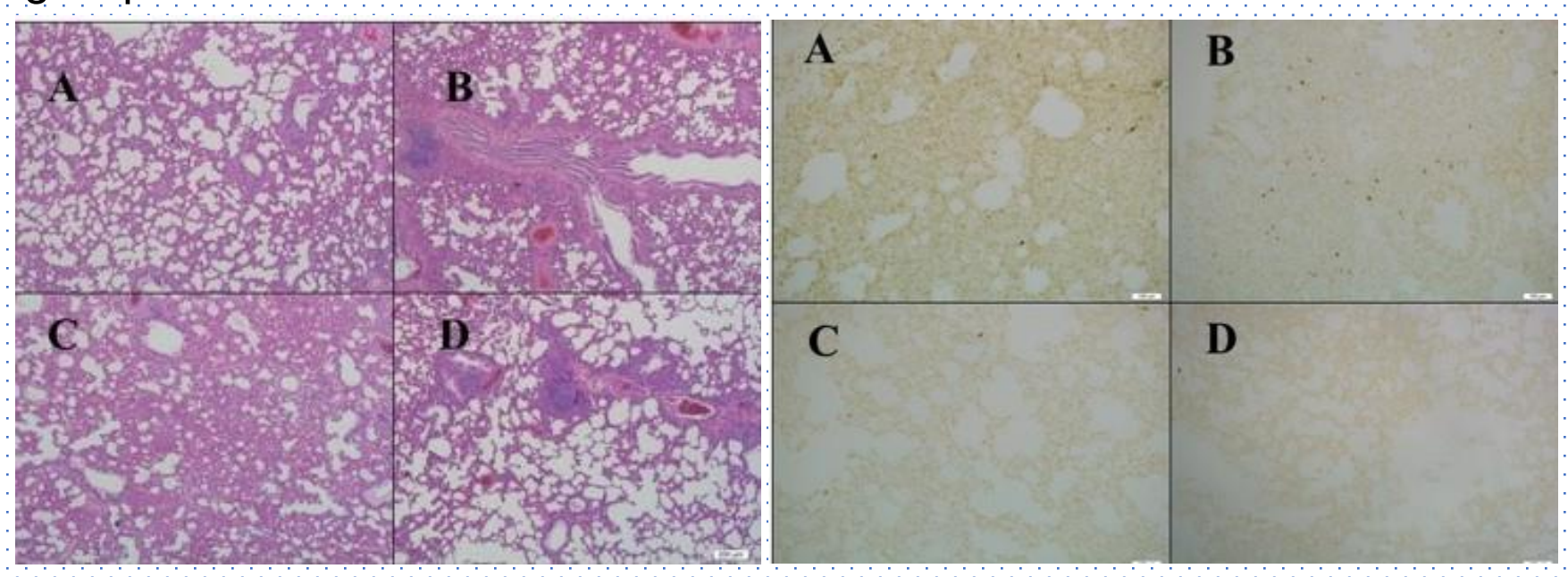

Figure 3 lmages of lung sections

\section{Conclusion}

The 3 present study demonstrated 3 that dexmedetomidine infusion at high dosage effectively suppressed the systemic nflammatory response, leukocyte mediated lung njury and apoptosis of lung tissue $A s$ a conclusion this experimental model provides that dexmedetomidine have a potential clinical application for reducing sepsis related lung injury
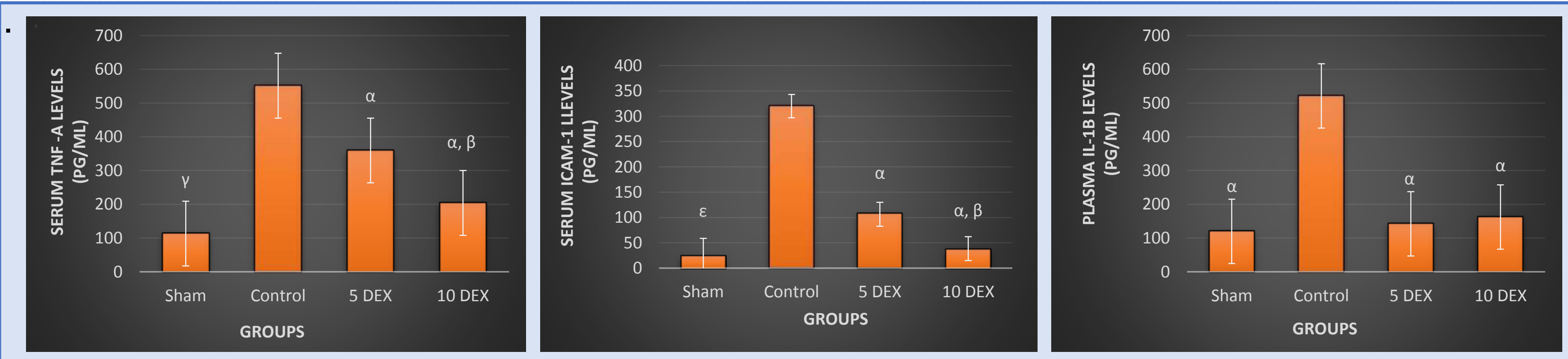

Figure 1. TNF- $\alpha$, IL-1 $\beta$, and ICAM- 1 concentrations in rats 6 hours after CLP 